\title{
Cavernous sinus thrombosis in a 14-year old boy
}

\author{
Kabelo Mokgacha1 ${ }^{1}$, Monde P. Maruza ${ }^{2}$, Sheikh O. Sesay ${ }^{3}$, Godfrey M. Rwegerera ${ }^{1,2}$ \\ Departments of ${ }^{1}$ Medicine and ${ }^{3}$ Radiology, Princess Marina Hospital; ${ }^{2}$ Department of Internal Medicine, University of \\ Botswana, Gaborone, Botswana. \\ Email: Godfrey.rwegerera@mopipi.ub.bw or godfreyrwegerera@gmail.com \\ Received: 11th October 2016, Revised: 21st February 2017, Accepted: 07th February 2018
}

\begin{abstract}
SUMMARY: Mokgacha K, Maruza MP, Sesay SO, Rwegerera GM. Cavernous sinus thrombosis in a 14-year old boy. Turk J Pediatr 2017; 59: 719-723.

Cavernous sinus thrombosis (CST) is a rare, life-threatening disorder occurring as a result of sepsis or secondary to aseptic causes in the setting of a thrombophilic disorder that has over the years been linked to high morbidity and mortality rates; this being despite availability of a wide number of new broad-spectrum antibiotics.

We present a case of a 14-year old boy who had presented with two weeks' duration of worsening bitemporal headache followed by facial swelling on the background history of chronic non-specific headache of few months duration. He was diagnosed to have cavernous sinus thrombosis secondary to pansinusitis. The course of his illness was complicated by a stroke despite prompt treatment with antibiotics and anticoagulation. The case highlights the importance of high index of suspicion in patients with unexplained headache and need for investigation and early referral to prevent occurrence of cavernous sinus thrombosis.
\end{abstract}

Key words: cavernous sinus thrombosis, sinusitis, stroke.

Cavernous sinus thrombosis (CST) is a rare, life-threatening disorder occurring as a result of sepsis or secondary to aseptic causes in the setting of a thrombophilic disorder. Septic causes include facial infection, sinusitis, orbital cellulitis, pharyngitis and otitis. Aseptic causes include trauma, surgery and pregnancy. CST is primarily diagnosed by symptoms and physical signs. ${ }^{1-6}$ Early diagnosis of CST with prompt antibiotic treatment is paramount as the condition continues to have high rates of morbidity and mortality. ${ }^{2,7}$

The clinical findings of sudden proptosis, accompanied by erythema of the eyelid, chemosis, and restricted ocular movements should alert the physician to the possibility of CST and prompt immediate treatment while awaiting radiological confirmation. ${ }^{1}$ Widespread use of antibiotics has made paranasal sinusitis surpass facial infections as cause of CST. Sphenoidal sinusitis is a significant cause of CST and occurs either on its own or in conjunction with other sinuses involvement. Infection spread from paranasal sinuses to cavernous sinus occurs either through direct extension or by retrograde thrombophlebitis along the ophthalmic veins. ${ }^{5,8}$ Use of anticoagulation either prophylactically/ early stage or in full blown disease (occluded cavernous sinus, bilateral involvement) is controversial. Recent evidence indicates that anticoagulation is more beneficial initially; however even in full blown disease benefits may outweigh associated complications. ${ }^{2}$

\section{Case Report}

A 14-year-old boy was referred to Princess Marina Hospital, a tertiary hospital in Gaborone, South-East of Botswana. He had presented at a local hospital with history of bitemporal headache of about 2 weeks duration, it was constant and sharp in character, exacerbated by movements and had worsened 3 days prior to admission; at the time it was also associated with vomiting. There was no associated history of auras, photophobia, seizures, pounding, painful eyes, ear discharge, red or painful eyes. There was no history of fever from the patient or from the referral note. Patient gave 
history of facial swelling that started 2 days prior to admission at a local hospital. It began on the right side and went on to affect the left side as well (could not give the timing). Past medical history was significant for mild headaches of over three months duration which were chronic and usually relieved by analgesia. There was no history of trauma, previous admissions or surgery to the head, and no known allergies. He was a form one student who came from a low socioeconomic background which was unremarkable for any significant chronic illnesses.

Examination of the patient revealed a young boy of good nutrition status with obvious facial swelling and bilateral peri-orbital swelling; he was not in any apparent cardio-pulmonary distress, body temperature was $38.2^{\circ} \mathrm{C}$ with no neck stiffness. He had bilateral facial tenderness, proptosis and bilateral conjunctiva redness. The conjunctiva redness was pronounced more on the left than right eye; eye movements were restricted in all directions. Fundoscopy showed evidence of papilledema in both eyes. The rest of the general and systemic examination was unremarkable.

Laboratory investigations were significant for leukocytosis of $16.2 \times 10^{9} / \mathrm{L}\left(4-10 \times 10^{9} / \mathrm{L}\right)$ with differential neutrophil count of $11.4 \mathrm{x}$ $10^{9} / \mathrm{L}\left(2-7 \times 10^{9} / \mathrm{L}\right)$ and lymphocyte count of $2.4 \times 10^{9} / \mathrm{L}\left(1-3 \times 10^{9} / \mathrm{L}\right.$; hemoglobin of $10.2 \mathrm{~g} / \mathrm{dl}(12-15 \mathrm{~g} / \mathrm{dl}), \mathrm{MCV}=81.1 \mathrm{fl}(83-99$ fl). Peripheral blood smear was not performed for this patient. Random blood glucose was $7.2 \mathrm{mmol} / \mathrm{L}$ with cerebrospinal fluid (CSF) parameters within normal ranges; specifically, CSF protein and glucose were $0.23 \mathrm{~g} / \mathrm{L}(0.18$ to $0.58 \mathrm{~g} / \mathrm{L})$ and $3.9 \mathrm{mmol} / \mathrm{L}(<16.7 \mathrm{mmol} / \mathrm{L})$, respectively. Differential diagnosis of septic cavernous sinus thrombosis was favored more than that of peri-orbital cellulitis and patient was immediately started on the following medications: metronidazole $500 \mathrm{mg}$ IV, TDS; vancomycin $600 \mathrm{mg}$ IV, BID; ceftriaxone $1.5 \mathrm{~g}$ OD, paracetamol $500 \mathrm{mg}$ PO, TDS and clexane $40 \mathrm{mg}$ S/C, BID. Computed tomography (CT)brain scan done on day 3 after admission showed; bilateral periorbital soft tissue swelling left more than right. There was opacification of the right frontal and right ethmoidal sinuses. Fluid level was noted in the left sphenoidal sinus (Fig. 1, 2 and 3). It was difficult to rule out CST from CT-Scan. There was no evidence of hemorrhage or abnormal extra-axial fluid collection demonstrated.

Patient's course in the hospital was prolonged as he developed a stroke on day 6 after admission with left sided hemiplegia and expressive aphasia. The power for all the muscle groups of both right upper and lower limbs was $5 / 5$. Subsequent CT-Scan was performed and it ruled out hemorrhage.

Blood cultures obtained on admission and during the course of treatment did not yield any growth. Patient made a slow progress with recovery over time; by day 18 , he was afebrile and remained afebrile thereafter with temperatures between $35.7^{\circ} \mathrm{C}$ and $36.8^{\circ} \mathrm{C}$, the facial swelling had completely resolved, by day 22 he was still aphasic and with right sided weakness. By day 25, he showed remarkable improvement, he could utter a few words and power of all muscle groups in the affected left side was now 2/5. The antibiotics and anticoagulation were stopped on day 28 of admission and he was discharged to continue follow up with physiotherapy, occupational therapy, medical and ENT clinics follow up; and speech therapy as outpatient.

\section{Discussion}

Cavernous sinus is an endothelium lined venous space, positioned lateral to the sella turcica on either side of sphenoid bone with wide connections to the veins around and veins draining the face. Structures passing through the wall of cavernous sinus include internal carotid artery, abducens, oculomotor, trochlear and divisions of trigerminal nerve. ${ }^{9,10}$

CST is a life-threatening infective condition associated with high mortality and morbidity ${ }^{11}$, less than half of the patients recover completely; the mortality rate is approximately $30 \%^{12-15}$ ; hence needing high index of suspicion for early diagnosis and intervention. ${ }^{12}$

Cavernous sinus thrombosis may result from infectious or non-infectious causes. ${ }^{16}$ Infectious causes include spread from oral cavity, paranasal sinuses, upper half of face, sides of the head and bacteremia. Non-infectious causes (aseptic) include neurological procedures or head injuries complicated by fractures of the anterior or middle cranial fossa. ${ }^{14,17}$ 
A

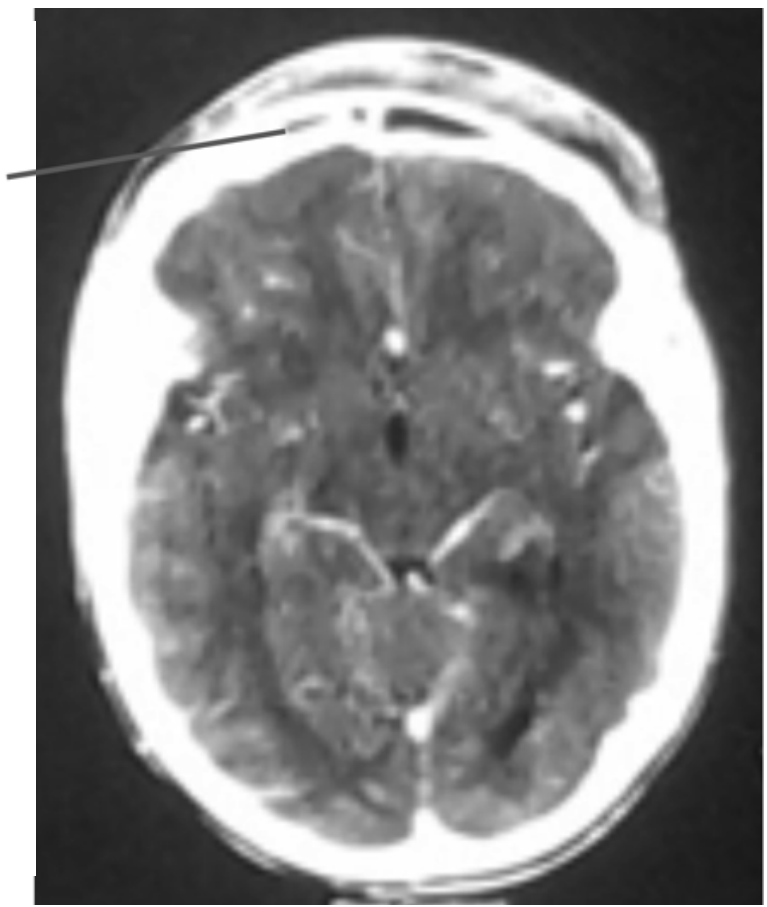

Fig. 1. Opacification of right frontal sinus (Label A).

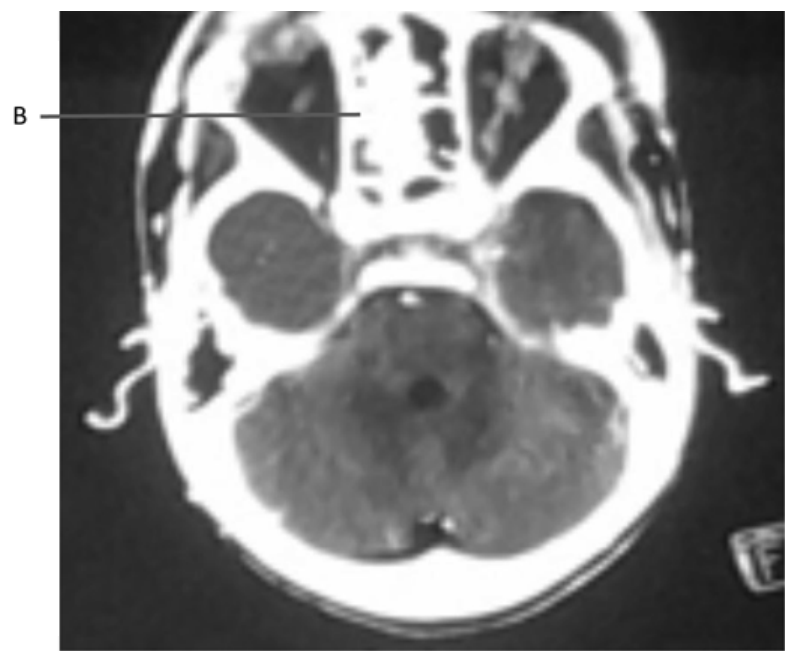

Fig. 2. Opacification of right ethmoid sinus (Label B).

Sphenoidal sinusitis has emerged as the most predisposing risk for CST due to the fact a sphenoidal sinus being a midline structure, it can present with either contralateral or bilateral complications. ${ }^{6,18}$ Our patient had pansinusitis making him at high risk for CST.

The patient presented in the case report had non-specific headache without any localizing signs for over three months; same presentation has been noted previously in paranasal sinus disease especially with sphenoid sinus

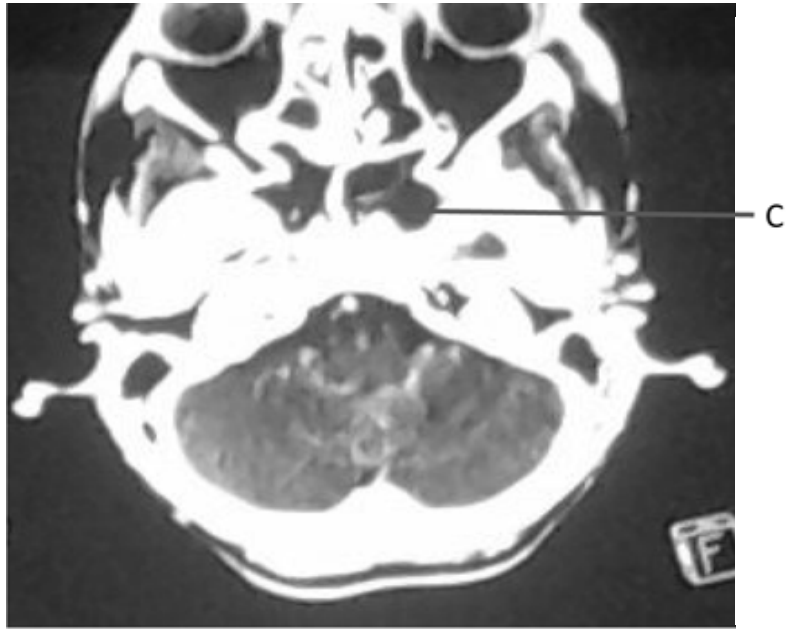

Fig. 3. Fluid level at left sphenoid sinus (Label C).

involvement, whereby patients were diagnosed after development of complications. ${ }^{19,20}$

Contrast-enhanced CT scan is useful in determining the cause of $\mathrm{CST}^{3,4,6,15,21}$ as it happened in this case report where it was revealed that patient had pansinusitis. On the other hand, the fact that CT scan was done after the patient had been on anticoagulation for past few days might have contributed to lesser radiological findings; likewise, contrasted CT scan and MRI may be normal; in such cases; High Resolution CT scan and MRI are more sensitive ${ }^{4,22}$, however the two diagnostic investigations are not available at our facility.

The disease is usually caused by Staphylococcus aureus, Streptococcus pneumoniae or other streptococci spp. Anaerobic bacteria should always be considered if the disease process continues despite antibiotics covering for grampositive organisms. ${ }^{2,20,21,23}$ Due to the severity of disease at presentation and the fact that we have not documented cases of CST in our setting, this being the first reported case; we decided to cover the patient with vancomycin and metronidazole to cover for possibility of methicillin-resistant Staphylococcus aureus and anaerobes respectively.

Antibiotics should be administered for an extended period, at least two weeks beyond the time of clinical resolution, because bacteria sequestered within the thrombus may not be killed until the dural sinuses have started to recanalize. Surgical intrusion into the cavernous sinus is difficult and not recommended. ${ }^{24}$ 
The role of anticoagulation has been contentious over the years as it was feared that its use may cause or exacerbate concurrent intracranial hemorrhage in patients with septic CST. Retrospective reviews of published reports indicate that hemorrhage caused by anticoagulation is rare, and that early adjunctive anticoagulation is beneficial in these patients if commenced after excluding the hemorrhagic sequela of CST radiologically. ${ }^{25}$ Early anticoagulants therapy reduced morbidity (blindness, stroke, opthmoplegia, hypopituitarism, focal seizures and vascular steal syndrome) whereas delayed or inadequate use provided no apparent benefit above antibiotic therapy alone. ${ }^{26}$

Use of anticoagulation has been backed recently by a randomized blinded controlled study of 20 patients with sinus venous thrombosis (10 heparin, 10 placebo) where the heparin group was significantly associated with both morbidity and mortality benefits compared to placebo group;-and intracranial hemorrhage a feared complication of anticoagulation was not significant in the heparin group compared to placebo, whenever it occurred it was more part of the disease entity. ${ }^{27}$ The presented patient was started on low molecular weight heparin from the outset in view of associated benefits of early anticoagulation. On the other hand, the patient had no focal neurological deficit to suggest a stroke at presentation and a brain CT could not be performed immediately to rule out hemorrhage. Though complicated with a stroke while on anticoagulation; possibility of hemorrhagic sequela was ruled out. Significant clinical recovery within three weeks of admission suggests that heparin might have played some role in the recovery process as per evidence of previous studies. ${ }^{26,28}$

The presented case report highlights the importance of high index of suspicion for paranasal sinusitis which can present with non-specific headache without localizing signs. Sinusitis can complicate to life threatening cavernous sinus thrombosis; the latter condition associated with high rates of morbidity and mortality. Use of anticoagulation has remained controversial, though recent evidence appears to shift supporting its use both in early stage and full-blown disease to prevent and reduce both high rates of morbidity and mortality secondary to cavernous sinus thrombosis.

\section{REFERENCES}

1. Yarington CT Jr. The prognosis and treatment of cavernous sinus thrombosis. Review of 878 cases in the literature. Ann Otol Rhinol Laryngol 1961; 70: 263-267.

2. Yarington CT Jr. Cavernous sinus thrombosis revisited. Proc R Soc Med 1977; 70: 456-459.

3. Ahmadi J, Keane JR., Segall HD, Zee CS. CT observations pertinent to septic cavernous sinus thrombosis. AJNR Am J Neuroradiol 1985; 6: 755-758.

4. Plewa MC, Dulebohn SC. Cavernous sinus thrombosis. https://www.ncbi.nih.gov/books/NBK448177/. (Accessed on 11 th April 2018).

5. Verma G, Tiwari A.K, Ahmad F, Gupta P. Cavernous sinus thrombosis: A case report. Arch CranOroFac Sc 2014; 1: 63-65.

6. Komatsu H, Matsumoto F, Kasai M, Kurano K, Daisuke Sasaki D, Ikeda K. Cavernous sinus thrombosis caused by contralateral sphenoid sinusitis: a case report. Head Face Med 2013; 9: 9.

7. Absoud M, Hikmet F, Dey P, Joffe M, Thambapillai E. Bilateral cavernous sinus thrombosis complicating sinusitis. J R Soc Med 2006; 99: 474-476.

8. Sofferman R.A. Cavernous sinus thrombophlebitis secondary to sphenoidal sinusitis. The Laryngoscope 1983; 93: 797-800.

9. Deshmukh V, Lakhkar B, Wagha J. Cavernous sinus thrombosis. Pediatr Oncall Journal 2008; 5.

10. Sara Fazio. Cranial-Nerve palsies and Oral Cancer NOW@NEJM.Acceseed on: http://blogs.nejm. org/now/index.php/cranial-nerve-palsies-and-oralcancer/2012/09/21/. Last accessed on 05th April 2017.

11. Rajendran R, Sivapathasundharam B. Shafer's Text Book of Oral Pathology. (5th ed). New Delhi: Reed Elsevier India Limited, 2008.

12. Ebright JR., Pace MT, Niazi AF. Septic thrombosis of the cavernous sinuses. Arch Intern Med 2001; 161: 2671-2676.

13. DiNubile MJ. Septic Thrombosis of the Cavernous Sinuses. Arch Neurol 1988; 45: 567-572.

14. Sharma R. (2016). Cavernous sinus thrombosis clinical presentation. http://emedicine.medscape.com/ article/791704-clinical. (Accessed on 05th April 2017).

15. Smith D, Vossough A, Vorona G, Beslow L, Ichord R, Licht D. Pediatric cavernous sinus thrombosis. A case series and review of the literature. Neurology 2015; 85: 763-769.

16. Mira F, Costa B, Catarina Paiva C, Andrês R, Loureiro A. Cavernous sinus thrombosis. Rev Bras Oftalmol. 2014; 73: 182-184.

17. Khan DM, Mohammad S, Hamid K, Nazeer AF, Gulab A. Cavernous sinus thrombosis. JPMI 1987; 2: 135141.

18. Pavlovich P, Looi A, Rootman J. Septic thrombosis of the cavernous sinus: two different mechanisms. Orbit 2006; 5: 39-43.

19. Dale BA, Mackenzie IJ. The complications of sphenoid sinusitis. J Laryngol Otol 1983; 97: 661-670. 
20. Southwick FS, Richardson EP Jr, Swartz MN. Septic thrombosis of the dural venous sinuses. Medicine (Baltimore).1986; 65: 82-106.

21. Sweis R, Biller J. Cavernous Sinus Thrombosis in Children. Pediatr Neurol Briefs 2016; 30: 4.

22. Schuknecht B, Simmen D, Yuksel C, Valavanis A. Tributary venosinus occlusion and septic cavernous sinus thrombosis: CT and MR findings. AJNR Am J Neuroradiol 1998; 19: 617-626.

23. Garrity, J. Cavernous Sinus Thrombosis. http://www. msdmanuals.com/professional/eye-disorders/orbitaldiseases/cavernous-sinus-thrombosis. (Accessed on 05 ${ }^{\text {th }}$ April 2017).
24. Karlin RJ, Robinson WA. Septic cavernous sinus thrombosis. Ann Emerg Med 1984; 13: 449-455.

25. Bhatia K, Jones NS. Septic cavernous sinus thrombosis secondary to sinusitis: are anticoagulants indicated? A review of the literature. The J Laryngol Otol 2002; 116: $667-676$.

26. Levine SR, Twyman RE, Gilman S. The role of anticoagulants in cavernous sinus thrombosis. Neurology 1988; 38: 517-522.

27. Einhäupl KM, Villringer A. Meister W, et al. Heparin treatment in sinus venous thrombosis. Lancet 1991; 338: 597-600.

28. Stam J, de Bruijn SF, DeVeber G. Anticoagulation for cerebral sinus thrombosis. Cochrane Database Syst Rev 2002; 4. 